\title{
Outcomes of multistage palliation of infants with functional single ventricle and heterotaxy syndrome
}

\author{
Bahaaldin Alsoufi, MD, ${ }^{\mathrm{a}}$ Courtney McCracken, PhD, ${ }^{\mathrm{b}}$ Brian Schlosser, BS, RDCS, \\ Ritu Sachdeva, MBBS, ${ }^{\mathrm{b}}$ Andrew Well, PhD, ${ }^{\mathrm{a}}$ Brian Kogon, MD, ${ }^{\mathrm{a}}$ William Border, MBChB, MPH, ${ }^{\mathrm{b}}$ and \\ Kirk Kanter, MD
}

\begin{abstract}
Background: Management of infants with heterotaxy syndrome and functional single ventricle is complicated due to associated cardiac and extracardiac anomalies. We report current era palliation results.
\end{abstract}

Methods: Between 2002 and 2012, 67 infants with heterotaxy syndrome underwent multistage palliation. Competing risks analyses modeled events after surgery (death vs Glenn procedure) and examined factors associated with survival. In addition, early and late outcomes following first-stage palliation surgery were compared with a matched contemporaneous control group of patients with nonheterotaxy single ventricle anomalies.

Results: Fifty-eight patients $(87 \%)$ required neonatal palliation, including a modified Blalock-Taussig shunt $(\mathrm{n}=34 ; 51 \%)$, Norwood operation $(\mathrm{n}=12$; $18 \%)$ or pulmonary artery band $(\mathrm{n}=12 ; 18 \%)$, whereas 9 patients $(13 \%)$ underwent a primary Glenn procedure. Competing risks analysis showed that at 1 year after first-stage palliation surgery, $29 \%$ of the patients had died or undergone transplantation and $63 \%$ had undergone a Glenn procedure. By 5 years after the Glenn procedure, $64 \%$ of patients had undergone a Fontan procedure. The overall 8-year survival rate was $66 \%$. On multivariable analysis, factors associated with mortality were unplanned reoperation (hazard ratio [HR], 2.9; 95\% confidence interval $[\mathrm{CI}], 1.1-7.3 ; P=.005)$ and total anomalous pulmonary venous connection repair (HR, 2.3; 95\% CI, 1.0-5.6; $P=.056)$. Comparison with the contemporaneous matched patients with nonheterotaxy single ventricle anomalies showed that first-stage palliation in the patients with heterotaxy was associated with a higher rate of in-hospital death $(27 \%$ vs $10 \% ; P=.022)$, and significantly longer durations of ventilation and intensive care unit stay. Interstage mortality, survival after the Glenn procedure, and progression to the Fontan procedure were comparable in the 2 groups.

Conclusions: The management of infants with heterotaxy and a functional single ventricle remains challenging. First-stage palliation is associated with high operative mortality and increased resource utilization owing to surgical morbidity. Nonetheless, outcomes beyond hospital discharge are comparable to those for patients with other single ventricle anomalies. Efforts to improve survival in those patients should focus on perioperative care. (J Thorac Cardiovasc Surg 2016;151:1369-77)

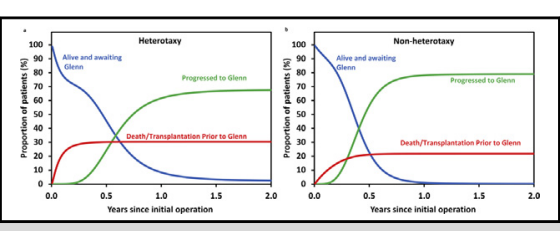

Competing events following palliation for heterotaxy syndrome versus nonheterotaxy syndrome single ventricle.

\section{Central Message}

Single ventricle palliation for heterotaxy syndrome is associated with higher morbidity and mortality than other single ventricle anomalies.

\section{Perspective}

First-stage palliation of infants with heterotaxy syndrome and functional single ventricle anomalies is associated with high operative mortality and increased resource utilization owing to surgical morbidity. Nonetheless, outcomes beyond hospital discharge are comparable to those in infants with other nonheterotaxy single ventricle anomalies.

See Editorial Commentary page 1378.
From the Divisions of a Cardiothoracic Surgery and ${ }^{\mathrm{b}}$ Cardiology, Children's Healthcare of Atlanta, Emory University School of Medicine, Atlanta, Ga.

Read at the 41st Annual Meeting of the Western Thoracic Surgical Association, Whistler, British Columbia, Canada, June 24-27, 2015.

Received for publication Sept 9, 2015; revisions received Dec 22, 2015; accepted for publication Jan 23, 2016.

Address for reprints: Bahaaldin Alsoufi, MD, Division of Cardiothoracic Surgery, Emory University School of Medicine, Children's Healthcare of Atlanta, 1405 Clifton Rd NE, Atlanta, GA 30322 (E-mail: balsoufi@hotmail.com). 0022-5223/\$36.00

Copyright (c) 2016 by The American Association for Thoracic Surgery http://dx.doi.org/10.1016/j.jtcvs.2016.01.054
Visceral heterotaxy syndrome is defined as an abnormality in which the internal thoracoabdominal organs demonstrate

Scanning this QR code will take you to supplemental figures and tables for this article. 


$$
\begin{aligned}
& \text { Abbreviations and Acronyms } \\
& \text { BTS }=\text { modified Blalock-Taussig shunt } \\
& \text { CI }=\text { confidence interval } \\
& \text { ECMO }=\text { extracorporeal membrane oxygenation } \\
& \text { HR }=\text { hazard ratio } \\
& \text { IQR }=\text { interquartile range } \\
& \text { LAI }=\text { left atrial isomerism } \\
& \text { OR }=\text { odds ratio } \\
& \text { PAB }=\text { pulmonary artery band } \\
& \text { RAI }=\text { right atrial isomerism } \\
& \text { TAPVC }=\text { total anomalous pulmonary venous } \\
& \text { connection }
\end{aligned}
$$

an abnormal arrangement across the body's left-right axis. ${ }^{1}$ Children born with heterotaxy syndrome often have complex congenital cardiac anomalies that require surgical intervention. Although some of these children have cardiac anomalies that are amenable to biventricular repair, many others have a functional single ventricle that requires multistage palliation, with the initial surgery dictated by the anatomy and the degree of systemic or pulmonary outflow obstruction. $^{1-8}$

Surgical management of children with heterotaxy syndrome and a functional single ventricle is challenging, owing to the presence of complex morphological features, such as total anomalous pulmonary venous connection (TAPVC), atrioventricular valve dysfunction, pulmonary atresia, arrhythmias, and heart block, all of which are established risk factors for increased morbidity and mortality following single ventricle palliation. $^{2-13}$ Additional extracardiac anomalies associated with heterotaxy syndrome, such as ciliary dysfunction, intestinal malrotation, and asplenia, can contribute to increased early operative morbidity and complexity of postdischarge management, further adversely affecting late outcomes in those challenging patients. ${ }^{7,11,12,14-17}$

We hypothesized that results of multistage palliation of neonates born with heterotaxy syndrome and functional single ventricle have improved in the current era, owing to advances in perioperative care and outpatient management, and that their palliation outcomes are comparable to those in neonates born with other nonheterotaxy single ventricle anomalies. To test this hypothesis, we examined early and late results following single ventricle palliation in infants with heterotaxy syndrome and compared them with those recorded in a matched group of contemporaneous infants with nonheterotaxy single ventricle anomalies at our institution.

\section{PATIENTS AND METHODS}

Between 2002 and 2012, 67 consecutive infants with heterotaxy syndrome underwent their first palliative surgery at Children's Healthcare of Atlanta, Emory University. Patients were identified using our institutional surgical database. Demographic, morphologic, clinical, operative, and hospital details were abstracted from the medical records for analysis. This study was approved by the hospital's Institutional Review Board, and the requirement for individual consent was waived for this observational study.

\section{Echocardiographic Data Collection and \\ Classification}

All preoperative echocardiograms were reviewed retrospectively by a single echocardiographer (B.S.). Our morphological inclusion criteria were based on the most recent nomenclature review and classification scheme reported by Jacobs and colleagues in $2007 .{ }^{1}$ In that report, heterotaxy syndrome is defined as an abnormality in which the internal thoracoabdominal organs demonstrate a abnormal arrangement across the body's left-right axis. By convention, heterotaxy syndrome does not include patients with either the expected usual or normal arrangement of the internal organs along the left-right axis, also known as "situs solitus," or patients with complete mirror-imaged arrangement of the internal organs along the left-right axis, also known as "situs inversus." ${ }^{1}$ Left atrial isomerism (LAI) is defined as a subset of heterotaxy syndrome in which some paired structures on opposite sides of the body's left-right axis are symmetrical mirror images of each other, and have the morphology of the normal left-sided structures. This condition is commonly associated with polysplenia. Right atrial isomerism (RAI) is a subset of heterotaxy syndrome in which some paired structures on opposite sides of the body's left-right axis are symmetrical mirror images of each other, and have the morphology of the normal right-sided structures. This is commonly associated with asplenia. ${ }^{1}$ All patients were considered to have a functional single ventricle, although some had 2 well-formed ventricles that were not considered amenable to septation owing to the presence of a noncommitted ventricular septal defect, multiple ventricular septal defects, or straddling of the atrioventricular valves.

\section{Follow-up}

Time-related outcomes were determined from recent office visits documented in the electronic chart of the Children's Healthcare of Atlanta system or from direct correspondence with pediatric cardiologists outside of the system. The mean duration of follow-up was $5.5 \pm 4.2$ years and was $94 \%$ complete.

\section{Statistical Analysis}

Data are presented as mean with standard deviation, median with interquartile range (IQR), or frequency and percentage, as appropriate. Timedependent outcomes after first- stage palliation surgery and after the Glenn operation were modeled parametrically. Parametric probability estimates for time-dependent outcomes uses models based on multiple overlapping phases of risk using PROC HAZARD (available for use with the SAS system at http://www.clevelandclinic.org/heartcenter/hazard). The HAZARD procedure uses maximum likelihood estimates to resolve risk distribution of time to event in up to 3 phases of risk (early decreasing or peaking hazard, constant hazard, and late increasing hazard). Maximum likelihood estimates are calculated iteratively using nonlinear optimization-based algorithms. Smoothed survival curves were generated using the HAZPRED procedure in SAS. PROC HAZPRED computes predictions for the survivorship and hazard functions along with their confidence limits.

Competing risks analysis was performed to model the probability over time of each of 2 mutually exclusive endpoints after first-stage palliation surgery: death/transplantation and survival to the Glenn procedure. After the Glenn procedure, competing risks models were not used, owing to the small number of death/transplantation events following this procedure.

For the outcome of hospital death following first-stage palliation, logistic regression was used to identify risk factors associated with hospital death. The following variables were tested: sex, age, weight, prematurity, extracardiac anomalies, heterotaxy syndrome type (RAI vs LAI), dominant ventricle morphology (left, right, or both), morphology of the atrioventricular valve (common atrioventricular valve, tricuspid valve, mitral valve, or all), antegrade pulmonary blood flow (absent, restricted, or unrestricted), 
TAPVC (absent, present unobstructed, or present obstructed), type of initial palliation surgery (Norwood, modified Blalock-Taussig shunt [BTS], pulmonary artery band $[\mathrm{PAB}]$, or primary Glenn procedure), concomitant TAPVC repair, postoperative extracorporeal membrane oxygenation (ECMO) support, and unplanned cardiac reoperation. To identify risk factors associated with death/transplantation following first-stage palliation surgery, parametric survival models were constructed using one risk factor at a time. The same variables listed above were tested. Given the limited sample size available for analysis, multivariable models were created using forward entry of variables significant at the .20 significance level on univariate analysis. Effects of covariates on the probability of outcomes in survival models are given as hazard ratio (HR) with $95 \%$ confidence interval (CI).

Neonates with heterotaxy syndrome and single ventricle anomalies who underwent first- stage palliation were compared with a propensity-matched contemporary cohort of neonates with single ventricle anomalies other than heterotaxy syndrome who also underwent first-stage palliation. Propensity score matching was performed to balance the 2 groups on baseline characteristics in a 1:1 ratio. In brief, multivariable logistic regression was used to predict patients with heterotaxy syndrome. Patient demographic and anatomic features considered in the logistic model included sex, age at initial surgery, prematurity, weight, first-stage palliation surgery, dominant ventricle, and the use of cardiopulmonary bypass during first-stage palliation surgery. The deviance test was used to measure the goodness of fit of the proposed logistic model.

For each patient, the multivariable logistic model was used to obtain the predicted probability, or propensity, of having heterotaxy syndrome. A 1:1 greedy matching algorithm was used to match the patients with and without heterotaxy syndrome based on their propensity scores. After matching, the matched cohort was then assessed to ensure a balanced distribution of covariates between the groups, using similar methods as described above in addition to presenting standardized mean differences. Statistical significance was assessed at the $P<.05$ level. All statistical analyses were performed using SAS version 9.3 (SAS Institute, Cary, NC).

\section{RESULTS}

\section{Patient Characteristics and Morphological and Operative Details}

Sixty-seven infants with heterotaxy syndrome had undergone initial palliation surgery. The cohort included 37 males $(55 \%)$ with a median age at surgery of 11 days (IQR, 5-50 days), and a median weight of $3.1 \mathrm{~kg}$ (IQR, $2.6-3.8 \mathrm{~kg})$, with 14 patients $(21 \%)$ weighing $\leq 2.5 \mathrm{~kg}$. Seventeen 7 patients $(25 \%)$ were born prematurely ( $\leq 36$ weeks gestation).

Complete morphological echocardiographic examination data were available for 66 patients and showed RAI in 42 patients $(64 \%)$ and LAI in $24(36 \%)$. The dominant ventricle morphology was dominant right in 32 patients $(48 \%)$, dominant left in 17 patients $(26 \%)$, and 2 equally formed ventricles in 17 patients $(26 \%)$. Fifty-eight patients $(88 \%)$ had a double-outlet right ventricle, and $53(80 \%)$ had a common atrioventricular valve. Overall, 33 patients $(50 \%)$ had TAPVC; types included supracardiac in 14 patients $(43 \%)$, cardiac in $9(27 \%)$, infracardiac in 6 $(18 \%)$, and mixed in $4(12 \%)$. Nine patients $(27 \%)$ had obstructed drainage at initial presentation. Antegrade pulmonary blood flow was absent in 16 patients $(24 \%)$, restricted in $27(40 \%)$, and unrestricted in $24(36 \%)$. Aortic arch obstruction was present in 13 patients (19\%), and aortic annulus hypoplasia was present in 12 patients $(18 \%)$. Twenty-three patients $(34 \%)$ had interrupted drainage of the inferior vena cava, and 43 patients $(64 \%)$ had a bilateral superior vena cava (Table 1).

Fifty-eight patients $(87 \%)$ required neonatal palliation, which included BTS in $34(51 \%)$, Norwood operation in $12(18 \%)$, and PAB in $12(18 \%)$. In the remaining 9 patients $(13 \%)$, primary Glenn bidirectional cavopulmonary shunt was the initial palliative surgery. In the 12 neonates who underwent Norwood operation, the source of pulmonary blood flow was a BTS in 3 and a Sano shunt in 9 . Concomitant surgery at the time of palliation was performed in 34 patients $(51 \%)$ and included TAPVC repair in $20(30 \%)$, atrioventricular valve repair in $4(6 \%)$, pulmonary artery augmentation in $10(15 \%)$, arch repair in 1 $(2 \%)$, and pacemaker implantation in $1(2 \%)$.

\section{Early Hospital Outcomes}

Following surgery, 8 patients $(12 \%)$ required ECMO support, 5 after TAPVC repair and BTS, 1 after BTS and unifocalization of interrupted branch pulmonary arteries plus pulmonary artery augmentation, and 2 after Norwood operation with BTS as the pulmonary blood flow source. Hospital survival for these 8 patients was $13 \%$ (1 of 8 ).

Nine patients $(13 \%)$ required early unplanned reoperation during the same hospital admission. These 9 reoperations included 4 following BTS and TAPVC repair ( 2 for tying the main pulmonary artery owing to overcirculation, 1 for shunt revision, and 1 for removing left atrial clots), 2 following BTS ( 1 for shunt revision and 1 for pulmonary artery augmentation), 2 following PAB (both for addition of BTS), and 1 following Norwood operation (for atrioventricular valve replacement). Hospital survival for the patients who underwent unplanned reoperation $44 \%$ (4 of 9).

In-hospital death occurred in 15 patients $(22 \%)$, including 9 following BTS, 3 following $\mathrm{PAB}$, and 3 following Norwood operation. Among these 15 patients, 9 $(60 \%)$ had undergone concomitant TAPVC repair and 3 $(20 \%)$ had undergone concomitant atrioventricular valve repair. Risk factors for in-hospital death are presented in Table 2. On multivariable analysis, concomitant TAPVC repair was significantly associated with in-hospital mortality (odds ratio, $4.8 ; 95 \% \mathrm{CI}, 1.1-21.0 ; P=.036$ ).

\section{Competing Risks Analysis After First-Stage Palliation Surgery}

Following the 58 neonatal first-stage surgeries, 15 patients $(26 \%)$ died in-hospital and $43(74 \%)$ were discharged alive. Two additional interstage deaths $(3 \%)$ occurred before the Glenn procedure, and 1 patient $(2 \%)$ underwent heart transplantation. The remaining 40 patients $(69 \%)$ progressed to receive the Glenn shunt.

Competing risks models showed that the proportion of patients who underwent the Glenn procedure began to rise 
TABLE 1. Comparison of patient characteristics, cardiac morphology, and postoperative details between patients with left atrial isomerism and patients with right atrial isomerism

\begin{tabular}{|c|c|c|c|}
\hline Variable & $\begin{array}{l}\text { Right atrial isomerism } \\
(\mathrm{n}=\mathbf{4 2})\end{array}$ & $\begin{array}{l}\text { Left atrial isomerism } \\
\qquad(\mathrm{n}=\mathbf{2 4})\end{array}$ & $P$ value \\
\hline \multicolumn{4}{|l|}{ Patient characteristics } \\
\hline Male sex, $\mathrm{n}(\%)$ & $22(52)$ & $14(58)$ & .640 \\
\hline Weight, kg, median (IQR) & $3.0(2.6-3.6)$ & $3.4(2.8-3.9)$ & .009 \\
\hline Weight $\leq 2.5 \mathrm{~kg}, \mathrm{n}(\%)$ & $9(21)$ & $4(17)$ & .755 \\
\hline Prematurity, n (\%) & $11(26)$ & $5(21)$ & .625 \\
\hline Age, d, median (IQR) & $10(5-50)$ & $14(5-49)$ & .695 \\
\hline \multicolumn{4}{|l|}{ Morphology } \\
\hline \multicolumn{4}{|l|}{ Dominant ventricle morphology, n (\%) } \\
\hline Left ventricle & $14(33)$ & $3(13)$ & .064 \\
\hline Right ventricle & $16(38)$ & $16(67)$ & \\
\hline Both ventricles & $12(29)$ & $5(21)$ & \\
\hline Atrioventricular septal defect, $\mathrm{n}(\%)$ & $37(88)$ & $16(67)$ & .053 \\
\hline Double-outlet right ventricle, $\mathrm{n}(\%)$ & $40(95)$ & $18(75)$ & .023 \\
\hline Anomalous pulmonary venous drainage, $\mathrm{n}(\%)$ & $32(76)$ & $1(4)$ & $<.001$ \\
\hline Obstructed pulmonary venous drainage, $\mathrm{n}(\%)$ & $9(21)$ & $0(0)$ & $<.001$ \\
\hline Aortic annulus hypoplasia, n (\%) & $2(5)$ & $10(42)$ & $<.001$ \\
\hline Aortic arch obstruction, n (\%) & $3(7)$ & $10(42)$ & .001 \\
\hline \multicolumn{4}{|l|}{ Pulmonary valve, $\mathrm{n}(\%)$} \\
\hline Unobstructed & $7(17)$ & $15(67)$ & $<.001$ \\
\hline Pulmonary stenosis & $21(50)$ & $6(25)$ & \\
\hline Pulmonary atresia & $14(33)$ & $2(8)$ & \\
\hline Interrupted inferior vena cava, $\mathrm{n}(\%)$ & $0(0)$ & $23(96)$ & $<.001$ \\
\hline Bilateral superior vena cava, $\mathrm{n}(\%)$ & $25(60)$ & $17(71)$ & .358 \\
\hline \multicolumn{4}{|l|}{ Operative and postoperative details } \\
\hline \multicolumn{4}{|l|}{ First palliative surgery type, $\mathrm{n}(\%)$} \\
\hline Modified Blalock-Taussig shunt & $28(67)$ & $6(25)$ & $<.001$ \\
\hline Norwood & $2(5)$ & $10(42)$ & \\
\hline Pulmonary artery band & $5(12)$ & $6(25)$ & \\
\hline Primary Glenn bidirectional shunt & $7(17)$ & $2(8)$ & \\
\hline Concomitant TAPVC repair, n (\%) & $19(45)$ & $0(0)$ & $<.001$ \\
\hline Cardiopulmonary bypass use, $\mathrm{n}(\%)$ & $29(69)$ & $15(63)$ & .587 \\
\hline Unplanned reoperation, n (\%) & $7(17)$ & $1(4)$ & .134 \\
\hline ECMO requirement, n (\%) & $6(14)$ & $2(8)$ & .700 \\
\hline Hospital death, $\mathrm{n}(\%)$ & $11(26)$ & $4(17)$ & .377 \\
\hline
\end{tabular}

at around 3 months after first-stage palliation and peaked at around 7 months. The hazard function for death before the Glenn procedure was characterized by the presence of an early risk phase during the initial 6 months that gradually diminished until it disappeared at approximately 1 year of age. Competing risks analysis showed that at 6 months after first-stage palliation surgery, $29 \%$ of the patients had died or undergone transplantation, $44 \%$ had undergone the Glenn procedure, and $27 \%$ were alive and awaiting a Glenn procedure. At 1 year, $29 \%$ of the patients had died or undergone transplantation, $63 \%$ had undergone the Glenn procedure, and $8 \%$ were alive and awaiting a Glenn procedure (Figure 1).

\section{Outcomes After Glenn Procedure}

Overall, 49 patients underwent the Glenn procedure, including 40 after first-stage palliation surgery and 9 as their primary surgery. Among these 49 patients, $16(33 \%)$ received a unilateral Glenn shunt and $33(67 \%)$ received bilateral Glenn shunts. Of note, 19 patients (39\%) had an interrupted inferior vena cava and thus underwent the Kawashima procedure at time of the Glenn procedure. Twenty patients required additional surgeries at the time of Glenn procedure, including 9 with pulmonary artery augmentation, 6 with atrioventricular valve repair, 5 with TAPVC repair, 3 with pacemaker implantation, 2 with atrial septectomy, and 2 with Damus-Kaye-Stansel anastomosis.

After the Glenn procedure, 23 patients $(47 \%)$ underwent the Fontan procedure, $3(6 \%)$ died before undergoing the Fontan procedure, and $23(47 \%)$ were alive and considered proper candidates for the Fontan procedure (including 12 patients who had undergone the Kawashima procedure). Concomitant surgeries at the time of the Fontan procedure included pulmonary artery augmentation in 3 patients, 
TABLE 2. Univariable analysis of hospital death following first-stage single ventricle palliation in neonates with heterotaxy syndrome

\begin{tabular}{lccc}
\hline \multicolumn{1}{c}{ Risk factor } & \multicolumn{3}{c}{$\mathbf{9 5 \% \text { confidence }}$} \\
\hline Prematurity & 0.68 & $(0.17-2.77)$ & .589 \\
Weight $\leq 2.5 \mathrm{~kg}$ & 0.93 & $(0.22-3.89)$ & .922 \\
Right atrial isomerism & 1.77 & $(0.50-6.34)$ & .378 \\
Dominant ventricle & & & \\
$\quad$ Left vs right & 3.06 & $(0.77-12.10)$ & .112 \\
$\quad$ Both vs right & 1.72 & $(0.40-7.50)$ & .468 \\
TAPVC & 2.52 & $(0.76-8.41)$ & .133 \\
Obstructed TAPVC & 3.76 & $(0.85-16.54)$ & .080 \\
Common atrioventricular valve & 4.31 & $(0.51-36.23)$ & .179 \\
Pulmonary valve & & & \\
$\quad$ Stenosis vs unobstructed & 0.68 & $(0.17-2.61)$ & .576 \\
$\quad$ Atresia vs unobstructed & 1.0 & $(0.23-4.31)$ & 1.00 \\
Concomitant TAPVC & 6.15 & $(1.77-21.31)$ & .004 \\
First palliative surgery type & & & \\
$\quad$ Norwood vs shunt & 0.93 & $(0.20-4.20)$ & .921 \\
$\quad$ Band vs shunt & 0.93 & $(0.20-4.20)$ & .921 \\
ECMO use & 44.6 & $(4.8-412.7)$ & $<.001$ \\
Unplanned reoperation & 4.88 & $(1.10-21.57)$ & .037 \\
\hline
\end{tabular}

$T A P V C$, Total anomalous pulmonary venous connection; $E C M O$, extracorporeal membrane oxygenation.

pulmonary venous stenosis repair in 2 patients, atrial septectomy in 1 patient, atrioventricular valve repair in 1 patient, and pacemaker implantation in 1 patient.

Competing risks models could not be applied following the Glenn procedure owing to the very low mortality rate. The proportion of patients who underwent the Fontan procedure began to rise at around 1.2 years after the Glenn procedure and peaked at around 1.9 years. By 5 years after the Glenn procedure, $64 \%$ of patients had undergone the Fontan procedure (Figure E1).

\section{Overall Survival and Risk Factors}

Parametric survival estimates for the entire cohort following surgery were $87 \%$ (95\% CI, 79\%-93\%) at 1 month, $71 \%(95 \% \mathrm{CI}, 60 \%-81 \%)$ at 1 year, and $66 \%$
(95\% CI, 54\%-77\%) at 8 years. The hazard function for death after surgery was characterized by the presence of an early risk phase during the first year postsurgery and a late low-risk phase that continued postsurgery with low attrition over time (Figure E2).

Risk factors affecting overall survival are presented in Table E1. On multivariable analysis, risk factors for overall mortality were ECMO use (HR, 7.9; 95\% CI, 3.2-19.4; $P<.001)$ and unplanned reoperation (HR, 3.6; 95\% CI, $1.5-8.9 ; P=.005)$. Given the strong correlation between concomitant TAPVC repair and ECMO use, concomitant TAPVC repair became a risk factor for overall mortality (HR, 2.3; 95\% CI, 1.0-5.6; $P=.056$ ) when ECMO use was removed from the multivariable model (Figure 2).

Although survival after primary Glenn procedure was $100 \%$ in our series, survival after first-stage palliation was not associated with the type of initial surgery on univariate analysis. Assessment of the effect of anatomic factors on survival revealed a trend toward improved survival in patients with LAI that did not reach statistical significance. Interestingly, a dominant right ventricle was associated with improved survival that did not reach statistical significance, suggesting that surgery type and coexisting anomalies play more important roles in survival than dominant ventricle morphology. Although the presence of obstructed TAPVC affected survival, the degree of pulmonary valve obstruction did not.

\section{Comparison With the Matched Patients With Nonheterotaxy Single Ventricle Anomalies}

Given that the mortality risk in our patients with heterotaxy syndrome was greatest after first-stage palliation surgery and decreased significantly following the Glenn procedure, we compared their data with findings in a matched control contemporaneous group of neonates with other forms of single ventricle anomalies who underwent first-stage palliation surgery (Table E1). The 2 groups were matched for age, sex, weight, prematurity, dominant
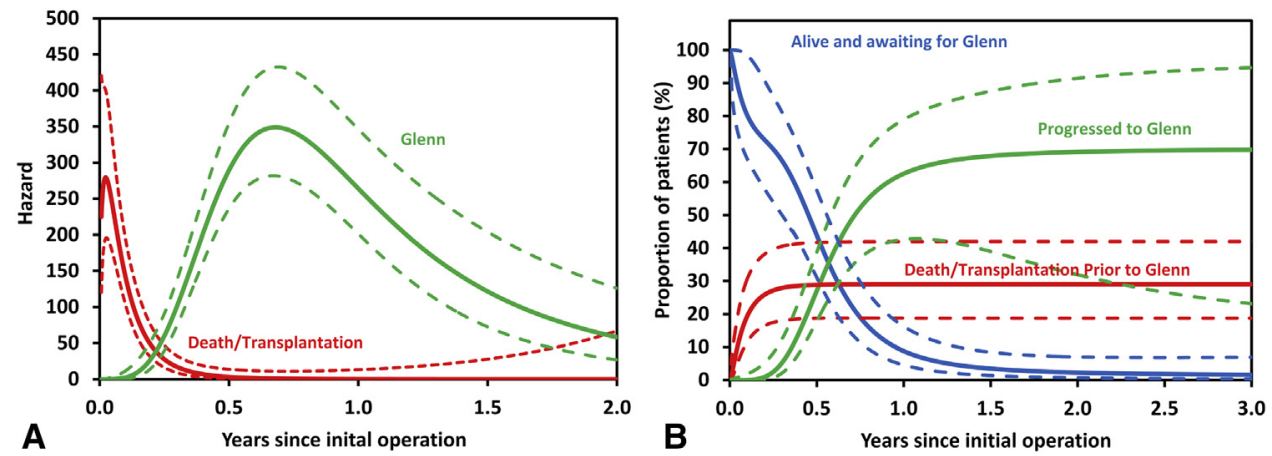

FIGURE 1. Competing risks analysis of outcomes after first-stage palliation surgery in 58 neonates with heterotaxy syndrome. The solid lines represent parametric point estimates, and the dashed lines enclose the $95 \%$ confidence interval. A, Competing hazard functions for each outcome. B, Proportion of neonates in each of the categories at any given time after first-stage surgery. 


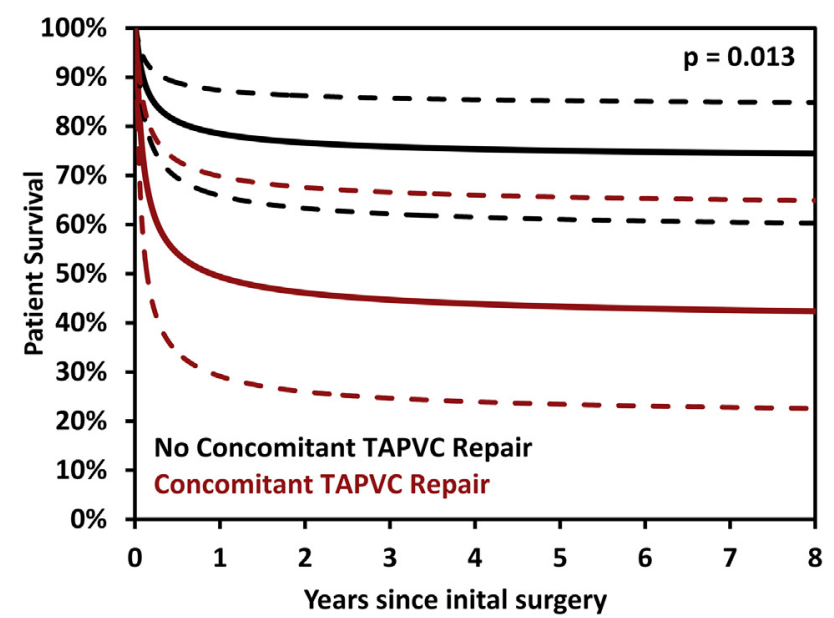

FIGURE 2. Parametric model for survival following initial palliation surgery in 67 infants with heterotaxy syndrome, stratified by the need for concomitant TAPVC repair. TAPVC, Total anomalous pulmonary venous connection.

ventricle, use of cardiopulmonary bypass, and type of firststage palliation (Table 3). The comparison showed a comparable rate of unplanned reoperation $(14 \%$ in the patients with heterotaxy syndrome vs $10 \%$ in controls; $P=.54$ ), a trend toward greater ECMO use in the heterotaxy syndrome group $(15 \%$ vs $6 \% ; P=.11)$, and significantly higher hospital mortality in the heterotaxy syndrome group $(27 \%$ vs $10 \% ; P=.022)$. In addition, the heterotaxy syndrome group had significantly longer durations of ventilation and intensive care unit stay (Table 3).

A comparison of the hazard of death before Glenn procedure in the 2 groups of patients showed a greater and more prolonged early risk of death in the heterotaxy syndrome group after first-stage palliation compared with controls. Nonetheless, the risk of interstage mortality and the rate of progression to subsequent Glenn procedure in hospital survivors were comparable in the 2 groups (Figure 3). Competing risks analysis of events after firststage palliation showed that at 1 month postsurgery, $19 \%$ of the heterotaxy syndrome group were dead or had undergone transplantation, compared with $7 \%$ of the control group. However, at 6 months after first-stage palliation surgery, these percentages were $30 \%$ in the heterotaxy syndrome group (ie, an additional $11 \%$ ) and $21 \%$ in the control group (ie, an additional 14\%), suggesting comparable interstage mortality in the 2 groups. In addition, at 1 year after first-stage palliation surgery, the number of patients alive and awaiting a Glenn procedure was comparable in the 2 groups ( $8 \%$ in the heterotaxy syndrome group vs $1 \%$ in controls), suggesting similar progression to subsequent Glenn procedure in hospital survivors in the 2 groups (especially when taking into account the higher incidence of interrupted inferior vena cava in the heterotaxy syndrome group, necessitating a delay in Glenn/Kawashima procedure). The hazard risk of death and overall survival in the 2 groups of patients are compared in Figure 4. Although the disparity in outcomes was noted in early-phase survival, survival was parallel in the 2 groups subsequent to that phase. Parametric survival at 8 years after first-stage palliation surgery was $62 \%$ (95\% CI, 48\%-74\%) for the heterotaxy syndrome group, compared with $75 \%$ (95\% CI, 61\%-85\%) for the control group $(P=.171)$.

\section{DISCUSSION}

Our study demonstrates that despite advances in the perioperative care of patients with single ventricle anomalies, the management of infants with heterotaxy syndrome and a functional single ventricle continues to be challenging and associated with high operative mortality and morbidity. Our findings are in agreement with previous reports of increased mortality risk in patients with heterotaxy syndrome after various palliative procedures, including modified BTS, Norwood operation, and PAB. ${ }^{1,18-21}$ Similarly, a recent Society of Thoracic Surgeons study examining hospital survival of 1505 patients with heterotaxy syndrome who underwent surgery found higher discharge mortality in patients with heterotaxy syndrome compared with those without heterotaxy syndrome for every procedure mortality risk category and for different subgroups of patients, such as those who received a BTS or underwent the Fontan procedure. ${ }^{1}$ Although several small studies have reported some encouraging results in patients with heterotaxy syndrome that seemed superior to older studies, ${ }^{22,23}$ this improvement has not been consistent, and a recent large series from Australia examining outcomes of 182 patients with heterotaxy syndrome report no improvement in survival over time. ${ }^{8}$

In our present series, we examined outcomes of neonates who underwent first-stage palliation and compared early and late results between those with heterotaxy syndrome and those with other nonheterotaxy single ventricle anomalies. Given the established risk factors associated with poor outcomes after single ventricle palliation, including low weight, prematurity, and genetic syndromes, ${ }^{21,24-27}$ we aimed to compare outcomes with those of a control group of patients without heterotaxy syndrome that was matched for those additional risk factors. In our matched comparison, the patients with heterotaxy syndrome continued to exhibit greater resource utilization (ie, duration of ventilation and intensive care unit stay), higher operative mortality, and lower overall survival. These findings suggest that heterotaxy syndrome is an independent risk factor associated with increased morbidity and mortality after single ventricle palliation.

Our findings are similar to those reported in a recent study from Washington, DC that compared outcomes in 84 patients with heterotaxy syndrome and 634 patients 
TABLE 3. Comparison of neonates with heterotaxy syndrome and single ventricle and a matched contemporaneous control group of neonates with other forms of single ventricle anomalies who underwent first-stage palliation surgery

\begin{tabular}{|c|c|c|c|c|}
\hline Variable & $\begin{array}{l}\text { Nonheterotaxy } \\
\quad(\mathbf{n}=\mathbf{5 2})\end{array}$ & $\begin{array}{l}\text { Heterotaxy } \\
\qquad(\mathrm{n}=52)\end{array}$ & $\begin{array}{c}\text { Standardized mean } \\
\text { difference }\end{array}$ & $P$ value \\
\hline \multicolumn{5}{|l|}{ Matched variables } \\
\hline Male sex, n (\%) & $33(64)$ & $30(42)$ & -0.12 & .55 \\
\hline Age, d, median (IQR) & $7(4-15)$ & $8(5-19)$ & 0.12 & .55 \\
\hline Weight, kg, median (IQR) & $3.2(2.7-3.5)$ & $3.0(2.6-3.4)$ & -0.06 & .78 \\
\hline Weight $\leq 2.5 \mathrm{~kg}, \mathrm{n}(\%)$ & $10(19)$ & $10(19)$ & 0.00 & 1.00 \\
\hline Premature $(<36 \mathrm{wk}), \mathrm{n}(\%)$ & $12(23)$ & $11(21)$ & -0.05 & .81 \\
\hline \multicolumn{5}{|l|}{ First palliation type, n (\%) } \\
\hline Modified Blalock-Taussig shunt & $22(42)$ & $28(54)$ & 0.38 & .17 \\
\hline Norwood & $21(41)$ & $12(23)$ & & \\
\hline Pulmonary artery band & $9(17)$ & $12(23)$ & & \\
\hline \multicolumn{5}{|l|}{ Dominant ventricle, $\mathrm{n}(\%)$} \\
\hline Right & $21(40)$ & $26(50)$ & 0.19 & .33 \\
\hline Left or both & $31(60)$ & $26(50)$ & & \\
\hline Cardiopulmonary bypass use, $\mathrm{n}(\%)$ & $26(50)$ & $30(58)$ & 0.15 & .43 \\
\hline \multicolumn{5}{|l|}{ Outcomes } \\
\hline Hospital death, n (\%) & $5(10)$ & $14(27)$ & 0.46 & .022 \\
\hline Hospital length of stay, $d$, median (IQR) & $16(12-24)$ & $24(14-41)$ & 0.48 & .018 \\
\hline ICU length of stay, h, median (IQR) & $154(98-286)$ & $269(158-636)$ & 0.58 & .007 \\
\hline Ventilator duration, h, median (IQR) & $102(54-243)$ & $185(74-475)$ & 0.19 & .028 \\
\hline Reoperation, n (\%) & $5(10)$ & $7(14)$ & 0.12 & .54 \\
\hline ECMO use, n (\%) & $3(6)$ & $8(15)$ & 0.32 & .11 \\
\hline
\end{tabular}

$I Q R$, Interquartile range; $I C U$, intensive care unit; $E C M O$, extracorporeal membrane oxygenation.

without heterotaxy syndrome with congenital heart disease and comparable Risk Adjustment in Congenital Heart Surgery 1 scores who underwent surgery at their institution. ${ }^{12}$ The heterotaxy syndrome group had greater postsurgical mortality, more postsurgical respiratory complications, and a more complicated postsurgical course. ${ }^{12}$ These same investigators posited that increased respiratory complications might be related to airway ciliary dysfunction, similar to that of primary ciliary dyskinesia. They suggested that future studies are warranted to examine gene mutations associated with ciliary dyskinesia and to assess the potential role of prophylactic treatment of patients with heterotaxy syndrome with therapies to improve mucus clearance in an effort to reduce respiratory complications and improve outcomes in these challenging patients. ${ }^{14,15}$

Along with ciliary dyskinesia, patients with heterotaxy syndrome often have other extracardiac malformations, such as intestinal malrotation, that may require surgery, which carries a risk of abdominal complications and asplenia, with a subsequent risk of sepsis. , $^{1,11,16,17}$ In our series, none of the early or late deaths was related to those additional extracardiac manifestations, suggesting that they might contribute to morbidity or longer hospitalization, but not necessarily to increased operative mortality, likely owing to improved awareness and management of existing malformations.
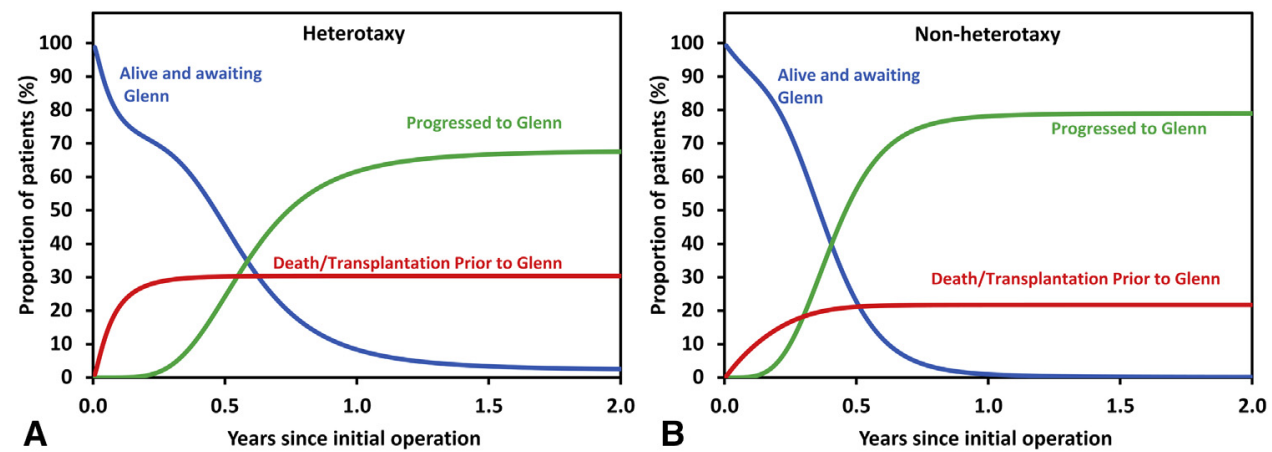

FIGURE 3. Competing risks analysis depiction of events following first-stage palliation in (A) neonates with heterotaxy syndrome and (B) a matched control group of neonates without heterotaxy syndrome with other forms of single ventricle anomalies. 


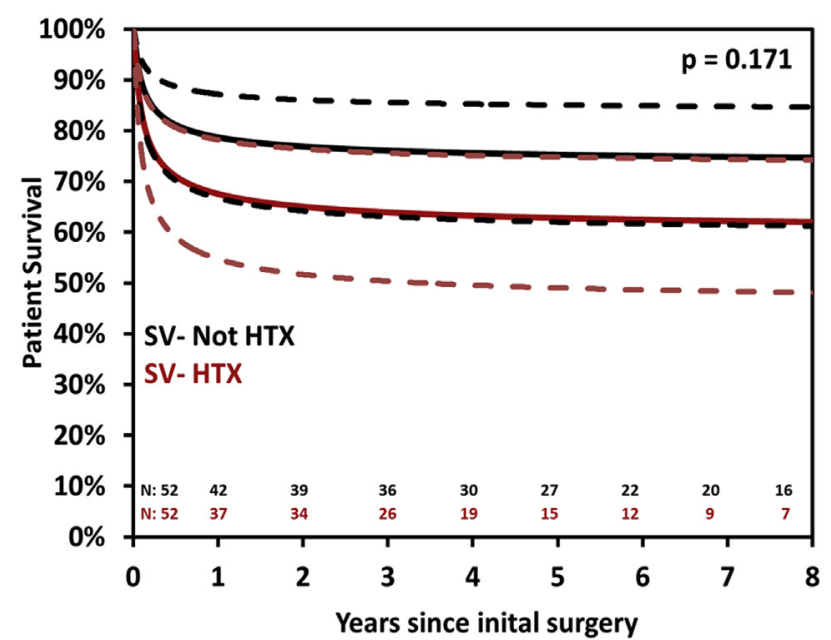

FIGURE 4. Time-dependent survival and risk hazard of death over time following first-stage palliation in neonates with heterotaxy syndrome and a matched control group of neonates without heterotaxy syndrome with other forms of single ventricle anomalies. SV, Single ventricle; $H T X$, heterotaxy syndrome.

On the other hand, the majority of hospital mortalities in our series were cardiac-related, highlighting the ongoing challenges in those patients related to the complexity of the intracardiac anatomy and the association with multiple anomalies that increase the risk of mortality, such as TAPVC, atrioventricular valve dysfunction, pulmonary atresia, arrhythmia, and heart block.

Atrioventricular valve regurgitation is common in patients with heterotaxy syndrome, especially in those with a common atrioventricular valve, ${ }^{1,5,7,8,23}$ and is a known risk factor for early and late mortality after single ventricle palliation. ${ }^{1,5,7,8,23,28}$ In our series, atrioventricular valve regurgitation or repair was not associated with increased mortality; however, this is likely due to our statistically small cohort size. Although there are reports of improved atrioventricular valve repair results in patients with heterotaxy syndrome, ${ }^{29}$ this issue remains a challenge associated with increased morbidity, increased need for unplanned reoperation, and decreased late survival. ${ }^{23,28}$ Similarly, we noted a trend toward worse survival in infants with pulmonary atresia that did not reach statistical significance, likely due to our small cohort size. In larger studies examining outcomes of palliation with BTS in patients with single ventricle anomalies, pulmonary atresia has been associated with increased mortality risk. ${ }^{18}$

On the other hand, concomitant TAPVC repair was significantly associated with increased operative mortality in our series, especially when performed for obstructed TAPVC during neonatal palliation. TAPVC repair in patients with heterotaxy syndrome is especially challenging and has been repeatedly associated with significantly worse early and late outcomes compared with simple TAPVC repair. ${ }^{9,10,30-32}$ Part of the challenge is related to the inability to accurately predict the amount of native pulmonary outflow obstruction except in patients with pulmonary atresia, as well as the existence of varying degrees of lung pathology and elevated pulmonary vascular resistance in patients with obstructed TAPVC, which complicates recovery after BTS surgery and compromises the ability to perform adequate PAB.

In addition to the high operative mortality after first-stage palliation surgery, late outcomes in patients with heterotaxy syndrome have been shown to be inferior owing to the emergence of problems related to arrhythmias, atrioventricular valve regurgitation, and pulmonary arteriovenous malformation in patients with an interrupted inferior vena cava. ${ }^{5,7,8,33-36}$ Several studies have reported inferior outcomes in children with heterotaxy syndrome after Glenn or Fontan surgery. ${ }^{33-36}$ In our series, outcomes seem to be comparable in patients with heterotaxy syndrome and those with nonheterotaxy single ventricle anomalies beyond hospital discharge, although our findings are limited by our small series and the intermediate nature of our follow-up.

\section{CONCLUSIONS}

Despite recent advances in the management of neonates undergoing multistage palliation of single ventricle anomalies, the management of patients with heterotaxy syndrome with a functional single ventricle remains challenging. Compared to patients without heterotaxy syndrome, those with heterotaxy syndrome experience greater operative mortality and resource utilization due to surgical morbidity following first-stage surgical palliation. Nonetheless, outcomes beyond hospital discharge are comparable in the 2 groups of patients, suggesting that efforts to improve survival in these difficult patients should focus on perioperative care.

\section{Conflict of Interest Statement}

Authors have nothing to disclose with regard to commercial support.

\section{References}

1. Jacobs JP, Pasquali SK, Morales DL, Jacobs ML, Mavroudis C, Chai PJ, et al. Heterotaxy: lessons learned about patterns of practice and outcomes from the congenital heart surgery database of the Society of Thoracic Surgeons. World J Pediatr Congenit Heart Surg. 2011;2:278-86.

2. Hashmi A, Abu-Sulaiman R, McCrindle BW, Smallhorn JF, Williams WG, Freedom RM. Management and outcomes of right atrial isomerism: a 26-year experience. J Am Coll Cardiol. 1998;31:1120-6.

3. Yun TJ, Al-Radi OO, Adatia I, Caldarone CA, Coles JG, Williams WG, et al. Contemporary management of right atrial isomerism: effect of evolving therapeutic strategies. J Thorac Cardiovasc Surg. 2006;131:1108-13.

4. Lim JS, McCrindle BW, Smallhorn JF, Golding F, Caldarone CA, Taketazu M, et al. Clinical features, management, and outcome of children with fetal and postnatal diagnoses of isomerism syndromes. Circulation. 2005;112:2454-61.

5. Jonas RA. Surgical management of the neonate with heterotaxy and long-term outcomes of heterotaxy. World J Pediatr Congenit Heart Surg. 2011;2:264-74. 
6. Takeuchi K, McGowan FX Jr, Bacha EA, Mayer JE Jr, Zurakowski D, Otaki M, et al. Analysis of surgical outcome in complex double-outlet right ventricle with heterotaxy syndrome or complete atrioventricular canal defect. Ann Thorac Surg. 2006;82:146-52.

7. Jacobs ML, Mavroudis C. Challenges of univentricular physiology in heterotaxy. World J Pediatr Congenit Heart Surg. 2011;2:258-63.

8. Bhaskar J, Galati JC, Brooks P, Oppido G, Konstantinov IE, Brizard CP, et al. Survival into adulthood of patients with atrial isomerism undergoing cardiac surgery. J Thorac Cardiovasc Surg. 2015;149:1509-13.

9. Khan MS, Bryant R III, Kim SH, Hill KD, Jacobs JP, Jacobs ML, et al. Contemporary outcomes of surgical repair of total anomalous pulmonary venous connection in patients with heterotaxy syndrome. Ann Thorac Surg. 2015;99: 2134-9.

10. Morales DL, Braud BE, Booth JH, Graves DE, Heinle JS, McKenzie ED, et al. Heterotaxy patients with total anomalous pulmonary venous return: improving surgical results. Ann Thorac Surg. 2006;82:1621-7.

11. Song J, Kang IS, Huh J, Lee OJ, Kim G, Jun TG, et al. Interstage mortality for functional single ventricle with heterotaxy syndrome: a retrospective study of the clinical experience of a single tertiary center. J Cardiothorac Surg. 2013; $8: 93$

12. Swisher M, Jonas R, Tian X, Lee ES, Lo CW, Leatherbury L. Increased postoperative and respiratory complications in patients with congenital heart disease associated with heterotaxy. J Thorac Cardiovasc Surg. 2011;141: 637-44.

13. Sinzobahamvya N, Arenz C, Reckers J, Photiadis J, Murin P, Schindler E, et al. Poor outcome for patients with totally anomalous pulmonary venous connection and functionally single ventricle. Cardiol Young. 2009;19:594-600.

14. Nakhleh N, Francis R, Giese RA, Tian X, Li Y, Zariwala MA, et al. High prevalence of respiratory ciliary dysfunction in congenital heart disease patients with heterotaxy. Circulation. 2012;125:2232-42.

15. Harden B, Tian X, Giese R, Nakhleh N, Kureshi S, Francis R, et al. Increased postoperative respiratory complications in heterotaxy congenital heart disease patients with respiratory ciliary dysfunction. J Thorac Cardiovasc Surg. 2014; 147:1291-8.e2.

16. Chiu SN, Shao PL, Wang JK, Chen HC, Lin MT, Chang LY, et al. Severe bacterial infection in patients with heterotaxy syndrome. J Pediatr. 2014;164: 99-104.

17. Sen S, Duchon J, Lampl B, Aspelund G, Bacha E, Krishnamurthy G. Heterotaxy syndrome infants are at risk for early shunt failure after Ladd procedure. Ann Thorac Surg. 2015;99:918-25.

18. Alsoufi B, Gillespie S, Kogon B, Schlosser B, Sachdeva R, Kim D, et al. Results of palliation with an initial modified Blalock-Taussig shunt in neonates with single ventricle anomalies associated with restrictive pulmonary blood flow. Ann Thorac Surg. 2015;99:1639-46.

19. Alsoufi B, Manlhiot C, Ehrlich A, Oster M, Kogon B, Mahle WT, et al. Results of palliation with an initial pulmonary artery band in patients with single ventricle associated with unrestricted pulmonary blood flow. J Thorac Cardiovasc Surg. 2015;149:213-20.

20. Jacobs JP, O'Brien SM, Chai PJ, Morell VO, Lindberg HL, Quintessenza JA. Management of 239 patients with hypoplastic left heart syndrome and related malformations from 1993 to 2007. Ann Thorac Surg. 2008;85:1691-6.

21. Alsoufi B, McCracken C, Ehrlich A, Mahle WT, Kogon B, Border W, et al. Single ventricle palliation in low-weight patients is associated with worse early and midterm outcomes. Ann Thorac Surg. 2015;99:668-76.
22. Ota N, Fujimoto Y, Murata M, Tosaka Y, Ide Y, Tachi M, et al. Improving outcomes of the surgical management of right atrial isomerism. Ann Thorac Surg. 2012;93:832-8.

23. Anagnostopoulos PV, Pearl JM, Octave C, Cohen M, Gruessner A, Wintering E, et al. Improved current era outcomes in patients with heterotaxy syndromes. Eur J Cardiothorac Surg. 2009;35:871-7.

24. Alsoufi B, Manlhiot C, Mahle WT, Kogon B, Border WL, Cuadrado A, et al. Low-weight infants are at increased mortality risk after palliative or corrective cardiac surgery. J Thorac Cardiovasc Surg. 2014;148:2508-14.e1.

25. Curzon CL, Milford-Beland S, Li JS, O'Brien SM, Jacobs JP, Jacobs ML, et al Cardiac surgery in infants with low birth weight is associated with increased mortality: analysis of the Society of Thoracic Surgeons Congenital Heart database. $J$ Thoracic Cardiovasc Surg. 2008;135:546-51.

26. Kalfa D, Krishnamurthy G, Duchon J, Najjar M, Levasseur S, Chai P, et al. Outcomes of cardiac surgery in patients weighing $<2.5 \mathrm{~kg}$ : impact of patientdependent and -independent variables. J Thorac Cardiovasc Surg. 2014;148 2499-506.e1.

27. Alsoufi B, Gillespie S, Mahle WT, Deshpande S, Kogon B, Maher K, et al. The impact of non-cardiac and genetic abnormalities on outcomes following neonatal congenital heart surgery. Semin Thorac Cardiovasc Surg. November 17, 2015 [Epub ahead of print].

28. Honjo O, Atlin CR, Mertens L, Al-Radi OO, Redington AN, Caldarone CA, et al. Atrioventricular valve repair in patients with functional single ventricle physiology: impact of ventricular and valve function and morphology on survival and reintervention. J Thorac Cardiovasc Surg. 2011;142:326-35.

29. Sano S, Fujii Y, Arai S, Kasahara S, Tateishi A. Atrioventricular valve repair for patient with heterotaxy syndrome and a functional single ventricle. Semin Thorac Cardiovasc Surg Pediatr Card Surg Annu. 2012;15:88-95.

30. Hancock Friesen CL, Zurakowski D, Thiagarajan RR, Forbess JM, del Nido PJ, Mayer JE, et al. Total anomalous pulmonary venous connection: an analysis of current management strategies in a single institution. Ann Thorac Surg. 2005; 79:596-606.

31. Lodge AJ, Rychik J, Nicolson SC, Ittenbach RF, Spray TL, Gaynor JW Improving outcomes in functional single ventricle and total anomalous pulmonary venous connection. Ann Thorac Surg. 2004;78:1688-95.

32. Caldarone CA, Najm HK, Kadletz M, Smallhorn JF, Freedom RM Williams WG, et al. Surgical management of total anomalous pulmonary venous drainage: impact of coexisting cardiac anomalies. Ann Thorac Surg. 1998;66: 1521-6.

33. Kim SJ, Kim WH, Lim HG, Lee JY. Outcome of 200 patients after an extracardiac Fontan procedure. J Thorac Cardiovasc Surg. 2008;136:108-16.

34. Alsoufi B, Manlhiot C, Awan A, Alfadley F, Al-Ahmadi M, Al-Wadei A, et al Current outcomes of the Glenn bidirectional cavopulmonary connection for single ventricle palliation. Eur J Cardiothorac Surg. 2012;42:42-8.

35. Lee TM, Aiyagari R, Hirsch JC, Ohye RG, Bove EL, Devaney EJ. Risk factor analysis for second-stage palliation of single ventricle anatomy. Ann Thorac Surg. 2012;93:614-8

36. Koudieh M, McKenzie ED, Fraser CD Jr. Outcome of Glenn anastomosis for heterotaxy syndrome with single ventricle. Asian Cardiovasc Thorac Ann. 2006;14: $235-8$.

Key Words: single ventricle, heterotaxy syndrome, Glenn, Fontan 

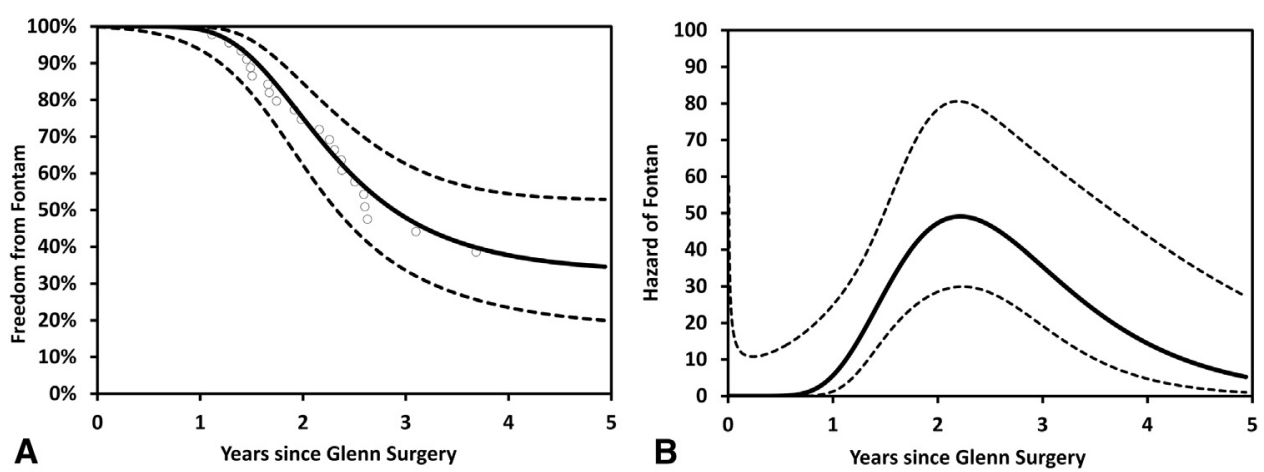

FIGURE E1. A, Proportion of patients without the Fontan operation and (B) hazard for the Fontan operation over time following the Glenn procedure in 49 infants with heterotaxy syndrome. The solid lines represent parametric point estimates, and the dashed lines enclose the $95 \%$ confidence interval. In A, the circles represent nonparametric estimates.
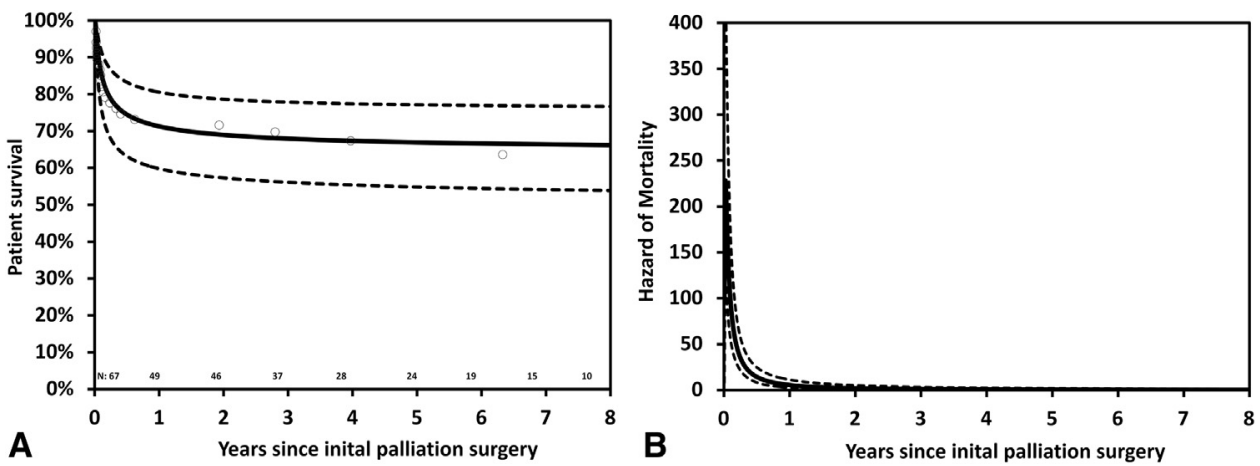

FIGURE E2. A, Time-dependent survival and (B) risk hazard of death over time following initial palliation surgery in 67 infants with heterotaxy syndrome. The solid lines in the parametric model represent parametric point estimates, and the dashed lines enclose the $95 \%$ confidence interval. In A, the circles represent nonparametric estimates. 
TABLE E1. Univariable model of overall survival following initial palliation in children with heterotaxy syndrome

\begin{tabular}{lccc}
\hline \multicolumn{1}{c}{ Risk factor } & $\begin{array}{c}\text { Hazard } \\
\text { ratio }\end{array}$ & $\begin{array}{c}\mathbf{9 5} \% \text { confidence } \\
\text { interval }\end{array}$ & $\begin{array}{c}\boldsymbol{P} \text { value } \\
\text { (early) }\end{array}$ \\
\hline Prematurity & 1.1 & $(0.4-2.8)$ & .176 \\
Weight $\leq 2.5 \mathrm{~kg}$ & 1.1 & $(0.4-3.0)$ & .202 \\
Right atrial isomerism & 2.1 & $(0.8-5.9)$ & .146 \\
Dominant ventricle & & & \\
$\quad$ Right vs not right & 0.70 & $(0.25-1.97)$ & .501 \\
$\quad$ Left vs not left & 1.20 & $(0.40-3.56)$ & .746 \\
TAPVC & 2.2 & $(0.9-5.1)$ & .084 \\
Common atrioventricular & 5.6 & $(0.8-41.5)$ & .094 \\
$\quad$ valve & & & .193 \\
Obstructed TAPVC & 2.1 & $(0.7-6.41)$ & \\
Pulmonary valve & & & .914 \\
$\quad$ Unobstructed vs stenosis & 1.1 & $(0.4-2.7)$ & .949 \\
$\quad$ Unobstructed vs atresia & 1.0 & $(0.3-3.2)$ & .013 \\
Concomitant TAPVC & 2.9 & $(1.3-6.7)$ & \\
First palliative surgery type & & & .608 \\
$\quad$ Shunt vs Norwood & 1.4 & $(0.4-4.1)$ & .679 \\
$\quad$ Shunt vs band & 1.3 & $(0.4-3.8)$ & $<.001$ \\
ECMO use & 9.9 & $(4.0-24.2)$ & .004 \\
Unplanned reoperation & 3.7 & $(1.5-9.2)$ & \\
\hline $\begin{array}{l}\text { TAPVC, Total anomalous pulmonary } \\
\text { membrane oxygenation. }\end{array}$ & & &
\end{tabular}

TABLE E2. Comparison of patient characteristics, cardiac morphology, and postoperative details between neonates with heterotaxy syndrome and single ventricle and contemporaneous neonates with other single ventricle anomalies who underwent firststage palliation surgery

\begin{tabular}{|c|c|c|c|}
\hline Variable & $\begin{array}{l}\text { Heterotaxy } \\
(\mathbf{n}=\mathbf{5 8}) \\
\end{array}$ & $\begin{array}{c}\text { Nonheterotaxy } \\
(\mathrm{n}=\mathbf{4 1 3})\end{array}$ & $P$ value \\
\hline \multicolumn{4}{|l|}{ Patient characteristics } \\
\hline Male sex, $\mathrm{n}(\%)$ & $32(55)$ & $249(60)$ & .46 \\
\hline Weight, kg, median (IQR) & $3.0(2.6-3.4)$ & $3.2(2.8-3.5)$ & .07 \\
\hline Weight $\leq 2.5 \mathrm{~kg}, \mathrm{n}(\%)$ & $14(24)$ & $54(13)$ & .025 \\
\hline Prematurity, n (\%) & $15(26)$ & $52(13)$ & .007 \\
\hline Age, d, median (IQR) & $8(5-21)$ & $5(4-9)$ & .002 \\
\hline $\begin{array}{l}\text { Chromosomal or } \\
\text { extracardiac anomaly }\end{array}$ & $2(3.5)$ & $51(12.4)$ & .045 \\
\hline \multicolumn{4}{|c|}{ Dominant ventricle morphology, $\mathrm{n}(\%)(\mathrm{n}=478)$} \\
\hline Left ventricle & $14(24)$ & $130(32)$ & $<.001$ \\
\hline Right ventricle & $29(50)$ & $271(66)$ & \\
\hline Both ventricles & $15(26)$ & $12(3)$ & \\
\hline \multicolumn{4}{|c|}{ Operative and postoperative details } \\
\hline \multicolumn{4}{|c|}{ First palliative surgery type, $\mathrm{n}(\%)$} \\
\hline $\begin{array}{l}\text { Modified Blalock- } \\
\text { Taussig shunt }\end{array}$ & $34(59)$ & $81(20)$ & $<.001$ \\
\hline Norwood & $12(21)$ & $271(66)$ & \\
\hline Pulmonary artery band & $12(21)$ & $61(15)$ & \\
\hline $\begin{array}{l}\text { Concomitant TAPVC } \\
\text { repair, } \mathrm{n}(\%)\end{array}$ & $17(30)$ & $4(0.1)$ & $<.001$ \\
\hline $\begin{array}{l}\text { Cardiopulmonary bypass } \\
\text { use, } \mathrm{n}(\%)\end{array}$ & $35(60)$ & $286(70)$ & .17 \\
\hline $\begin{array}{l}\text { Unplanned reoperation, } \\
\text { n }(\%)\end{array}$ & $9(16)$ & $45(11)$ & .30 \\
\hline ECMO requirement, $\mathrm{n}(\%)$ & $8(14)$ & $43(10)$ & .44 \\
\hline
\end{tabular}

